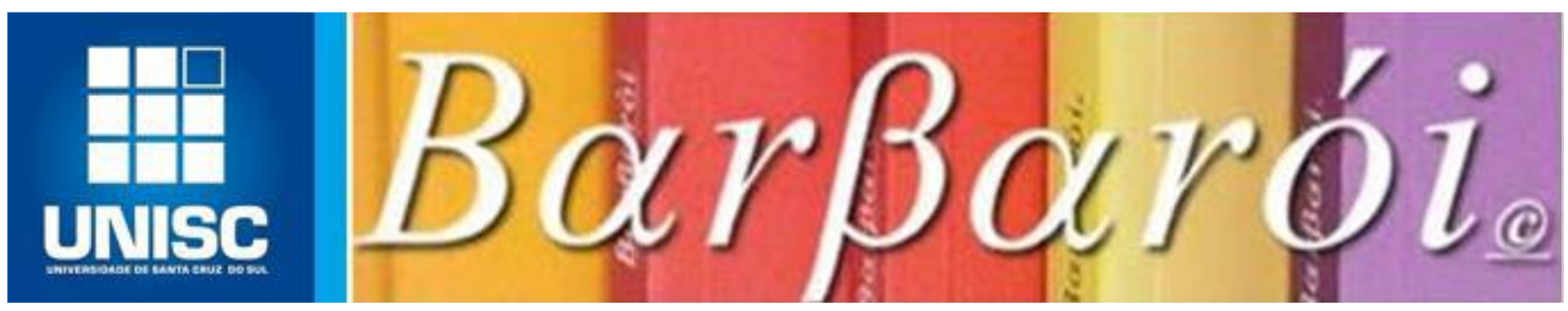

\title{
A (IN) VISIBILIDADE DO ACOLHIMENTO NO ÂMBITO DA SAÚDE: EM PAUTA AS EXPERIÊNCIAS DE INTEGRANTES DA COMUNIDADE LGBTQIA+
}

\author{
DOI: http://dx.doi.org/10.17058/barbaroi.v0i58.14765
}

$*$

Nizar Amin Shihadeh

Universidade Federal do Pampa - UNIPAMPA - Brasil

Elisângela Maia Pessoa

Universidade Federal do Pampa - UNIPAMPA - Brasil

Fabiane Ferreira da Silva

Universidade Federal do Pampa - UNIPAMPA - Brasil

\section{Resumo}

O presente artigo apresenta resultados de pesquisa que buscou investigar como os serviços de saúde podem (in) visibilizar atendimento ao público LGBTQIA+. O tema torna-se relevante à medida que discute a necessidade de acolhimento qualificado, bem como sua implicação na vida de lésbicas, gays, bissexuais, travestis, transexuais e transgêneros que buscam acessar serviços de saúde e que de alguma forma podem acabar sofrendo algum tipo de violência - nem sempre intencional - profissional ou institucional. Realizou-se pesquisa qualitativa via amostra intencional, onde foram realizadas entrevistas com onze integrantes da comunidade LGBTQIA+. Os dados foram analisados via análise conteúdo à luz do método dialético crítico. A partir dos dados coletados e reflexões geradas, fica evidente que cotidianamente ocorrem ações caracterizadas como LGBTQIAfobia. Não raro, no acolhimento perdura questões preconceituosas e de desrespeito a dignidade humana. Fica evidente, a necessidade de capacitações, diálogos e respeito à legislações que aparam o atendimento em saúde de forma ampliada.

Palavras-chave: Saúde Coletiva; LGBTQIA+; Acolhimento.

\section{Introdução}

Falar de identidade de gênero e orientação sexual ainda tem sido considerado tabu, em uma sociedade pautada na heteronormatividade e no machismo que gera violência, exclusão, opressão e todo o tipo de ação que pode colocar a margem da sociedade tudo que é considerado 
fora do padrão moralmente aceito. Nesse sentido, a população LGBTQIA ${ }^{1}{ }^{1}$, frequentemente passa ser marginalizada e violentada por conta de impactos gerados por atitudes preconceituosas que podem influenciar no seu bem-estar social, na saúde, no trabalho e no meio onde vivem. Ressalta-se o fato de questões culturais poderem influenciar, de modo subjetivo, o atendimento dos/as profissionais da saúde, o que os/as leva a assistir todos/as os/as usuários/as como se fossem heterossexuais, podendo gerar situações graves de discriminação e preconceito contra lésbicas, gays, bissexuais, travestis e transexuais (CARDOSO, FERRO, 2012).

As consequências causadas pela rejeição social resultam em discriminações e exclusões refletindo na forma de atendimento e acolhimento que esses sujeitos recebem em diversas instituições, pautado em intervenções na maioria das vezes não humanizadas. Tão importante se constitui o ato de acolhimento institucional, que o mesmo compõe uma das diretrizes da Política Nacional de Humanização - PNH (2010). O acolhimento pode ser definido como a junção dos serviços de saúde, tanto no primeiro contato com o usuário/a - que deve ser exercido de forma cortês e responsável -, quanto durante o processo de acompanhamento e/ou tratamento dos/as mesmos/as. O acolhimento deve estar associado a uma prática ética quando dispensada a atenção ao/a usuário/a, em outras palavras, acolher é um compromisso de resposta às necessidades dos/as cidadãos/as que procuram os serviços de saúde. Ainda quanto ao acolhimento a PNH (2010) indica que acolher é reconhecer o que o outro traz como legítimo e singular em sua necessidade de atendimento à saúde, assim o acolhimento deve sustentar a relação entre equipes/serviços e usuários/ populações. A PNH (2010) ainda, indica que o acolhimento deve ser construído de forma coletiva, com análise a partir da prática e troca geradas nos processos de trabalho que vem buscar a construção de relações de confiança, compromisso e vínculo entre as equipes/serviços, trabalhador/equipes e usuário com sua rede socio afetiva.

Nem todos/as profissionais tem um olhar ampliado e escuta sensível, deixando passar despercebidas situações de constrangimento e violência institucional, o que pode afastar os sujeitos de um possível tratamento inicial, fragilizando dessa forma, à atenção básica, principalmente quanto a integralidade e a equidade da atenção à saúde. Destaca-se que a

\footnotetext{
${ }^{1}$ Lésbica: mulher que se relaciona afetiva e sexualmente com outra mulher; Gay: homem que se relacionam afetiva e sexualmente com outro homem; Bisssexual: pessoa que se relaciona afetiva e sexualmente com pessoas de ambos os sexos/gêneros; Travesti: se identifica com um gênero diferente ao que foi registrado ao nascer, mas não se incomoda com a genitália; Homem Transexual: foi registrado como 'mulher' ao nascer, mas se identifica como homem, Mulher Transexual: foi registrada como 'homem' ao nascer, mas se identifica como mulher (ambos as vezes são chamados de transexuais se desejam assistência médica para a transição de um sexo para outro.); Transgênero: pessoa que têm uma identidade de gênero, ou expressão de gênero diferente de seu sexo atribuído (BRASIL, 2008).
}

Barbarói, Santa Cruz do Sul, n. 58, p.<172-194>, jan/jun 2021 
garantia de acesso à saúde está preconizada como direito na Constituição Cidadã (1988), fruto de grande mobilização social, que com a luta dos movimentos sociais ganhou o nome de "Movimento pela Reforma Sanitária”. Assim, a saúde passou a ser integrante do sistema de Seguridade Social em decorrência do conceito ampliado de saúde, ou seja, ser saudável não é só a ausência de doença, mas o acesso a direitos básicos e sociais como educação, moradia, alimentação, etc. Todos/as, independentemente de sua identidade de gênero ou orientação sexual devem ter acesso aos serviços de saúde de forma igualitária, em garantia da dignidade da pessoa humana.

Nesse contexto o presente artigo intui apresentar resultados de uma pesquisa cujo objetivo geral foi: Investigar como os serviços de saúde podem (in) visibilizar o atendimento ao público LGBTQIA $+^{2}$. O estudo ainda teve como pretensão: problematizar como vem ocorrendo o acolhimento da comunidade LGBTQIA+ nos serviços de saúde; verificar se há ocorrência de LGBTQIAFobia $^{3}$ institucional; identificar se há e quais são os serviços e rede de atendimento ao público LGBTQIA+; indicar possibilidades de melhoria no atendimento e pontuar diante dos resultados, possibilidades de intervenção no âmbito da saúde coletiva. Destaca-se a importância de identificar se ocorre ou não violência institucional no trato a esse público, assim como também entender como ocorre o atendimento desses sujeitos na rede de serviços e como se dá o acolhimento nesses espaços, visando indicar possibilidades de melhorias tornando essa abordagem mais humanizada e qualificada. Ressalta-se que a pretensão da pesquisa realizada não reside na culpabilização dos serviços e profissionais enquanto "inquisição", mas sim no sentido de promoção de debates que venham informar e garantir melhorias nos serviços de saúde.

\section{Percurso metodológico da pesquisa}

O método adotado enquanto fio condutor de análise da realidade para a realização da pesquisa realizada foi o dialético-crítico, que possui como categorias centrais a totalidade, a historicidade e a contradição, buscando explicações coerentes, lógicas e racionais, para assim

\footnotetext{
2 Termos utilizados na obra de Guilherme Bortoletto LGBTQIA+: identidade e alteridade na comunidade. " $i$ " de intersex, o "q" de queer (em português, 'excêntrico", 'insólito') é um termo "guarda-chuva" proveniente do inglês usada para designar pessoas que não seguem o modelo de heterossexualidade ou do binarismo de gênero. e o "a" de agêneros e assexuados e o "+”, que vem a indicar a possibilidade da inclusão de novas homossexualidades. Basta concluir por ora que a denominação é aberta e sempre sujeita a mudanças.

${ }^{3}$ Supremo Tribunal Federal (STF) determinou no dia 13 de junho de 2019, que a discriminação por orientação sexual e identidade de gênero passe a ser considerada um crime, determinando que a conduta passe a ser punida pela Lei de Racismo (7716/89), que hoje prevê crimes de discriminação ou preconceito por "raça, cor, etnia, religião e procedência nacional.
}

Barbarói, Santa Cruz do Sul, n. 58, p.<172-194>, jan/jun 2021 
tentar entender a realidade que procura-se investigar não se tratando de algo pronto e inacabado pois precisa-se construir caminhos para poder analisar possibilidades de encontrar possíveis transformações para não correr o risco de apresentar opiniões pré-concebidas. Este método contribui para o desvendamento do real e assim buscar compreender os aspectos contraditórios manifestados nas desigualdades e resistências que se conformam nas expressões da questão social, para tanto utilizou-se das categorias: historicidade, contradição e totalidade. Conforme Pessôa (2010, p. 27):

A categoria Historicidade envolve diretamente a vida dos indivíduos, pois se estabelece um ciclo de fenômenos. O movimento é uma qualidade inerente a todas as coisas; a sociedade e a natureza não são entidades acabadas; estão em constante transformação, ou seja, sempre inacabadas.

A categoria contradição torna necessário pensar a realidade e aceitar a contradição para chegar ao concreto Marx (1980, p. 74) salienta que "a contradição da realidade é a forma da mesma se mover, é a forma de colocar em movimento, o tempo todo, esse destino do ser, da realidade, que é ser móvel”. Já a categoria totalidade permite estudar um contexto de forma mais ampla proporcionando assim condições de entender a situação a qual buscamos investigar. Conforme Pessôa (2010 p.27) "a posição da totalidade compreende a realidade em suas íntimas leis e revela, sob a superfície e a casualidade dos fenômenos, as conexões internas". É elementar enxergar o mundo tal como ele é hoje a partir do que ele deveria ser e ao mesmo tempo observando os obstáculos, para então criar mecanismos de transformação ainda que as situações que se apresentem parecem ser impossíveis.

O tipo de pesquisa escolhida foi a qualitativa, esta trabalha com o universo dos significados, dos motivos, das aspirações, das crenças, dos valores e das atitudes, sendo esses fenômenos humanos classificados como parte da realidade social (MARTINELLI, 1999). O objeto de estudo deste tipo de pesquisa se resume no mundo das relações, das representações e da intencionalidade, não podendo ser expresso em números e indicadores quantitativos, assim não se prioriza a quantidade de sujeitos alcançados, mas o significado de falas e pensar sobre determinado objeto. Assim,

A pesquisa qualitativa responde a questões muito particulares. Ela se preocupa, nas ciências sociais, com um nível de realidade que não pode ser quantificado, ou seja, ela trabalha com o universo de significados, motivos, aspirações, crenças, valores e atitudes, o que corresponde a um espaço mais profundo das relações dos processos e dos fenômenos que não podem ser reduzidos à operacionalização de variáveis (MINAYO, 1995, p. 21-22)

Embora a amostra tenha sido intencional, ou seja, quando os sujeitos que compõem a amostra são escolhidos por terem afinidade com o objeto de estudo - no caso aqui sujeitos que fazem parte de comunidades LGBTQIA+ - a amostra não foi fechada, pois utilizou-se da 
técnica denominada bola de neve para seleção e posteriormente saturação de coleta de dados. Para técnica de bola de neve ou snowball, escolhe-se um sujeito para iniciar o estudo este será nomeado como "semente". A semente desse projeto foi escolhida a partir de indicações de profissionais de determinada unidade de Estratégia de Saúde da Família - da cidade de realização da pesquisa - a partir de usuários/as que frequentam o referido espaço institucional e se identificam abertamente como membros de comunidade LGBTQIA+. A partir da indicação foi realizada visita domiciliar para apresentar o projeto onde foi realizado o convite para participação na pesquisa, mediante aceite foi apresentado o Termo de Consentimento Livre e Esclarecido. Após conclusão da entrevista, voluntariamente o/a participante indicava outro membro da comunidade. A partir da saturação de coleta de dados a pesquisa foi realizada a partir da experiencia de onze sujeitos. Destaca-se que o método bola de neve não segue uma regra numérica, a partir da indicação das sementes a rede poderá ou não aumentar visto que os sujeitos procurados não foram ao acaso, mas a partir de características específicas importantes para a pesquisa e assim prezando pelo respeito à autonomia e a liberdade de aceitação ou não.

Essa estratégia resolve o problema de acesso de forma conveniente: pelo menos se conhece alguém que pode ser observado ou entrevistado, e pode-se tentar fazer com que este indivíduo o apresente a outros e seja seu fiador, desse modo deflagrando uma espécie de amostragem em bola de neve (BECKER, 1993, p. 155).

Como critério de inclusão foi estabelecido que todos/as os sujeitos fossem membros de comunidade LGBTQIA+, sendo os/as mesmo com idade a partir dos 18 anos. Enquanto critério de exclusão foram liberados sujeitos que declararam não ter acessado serviços no âmbito da saúde ou apresentassem conflitos de interesse em decorrência do grau de parentesco com profissionais da rede de saúde.

A técnica de coleta de dados utilizada foi a entrevista semi-estrutura com aplicação de instrumento de coleta denominado formulário de entrevista com perguntas abertas e fechadas. Destaca-se que a entrevista semi-estruturada, abrange perguntas pré-estabelecidas pelo pesquisador que está livre para ir além, podendo elaborar perguntas que tomem as respostas mais completas. Assim,

A realização de entrevistas de pesquisa é muito mais complexa que entrevistas para fins de aconselhamento ou seleção de pessoal. Isso porque a pessoa escolhida não é a solicitante. Logo, o entrevistador constitui a única fonte de motivação adequada e constante para o entrevistado. Por essa razão, a entrevista nos levantamentos deve ser desenvolvida a partir de estratégia e tática adequadas (GIL, 2002, p. 117).

Considerando a escassez de tempo as entrevistas não foram gravadas mas as respostas anotadas pelos/as pesquisadores/as. Em preservação as questões éticas após apresentação do projeto apresentava-se o TCLE. A partir do aceite e assinatura do termo foi realizada a 
entrevista em horário e local de escolha do/a sujeito a ser entrevistado, não sendo as mesmas realizadas em ambiente institucional, mas sim no domicílio ou local apropriado indicado pelos entrevistados/as. Somente foram divulgados os dados coletados, sendo assim os nomes das pessoas foram identificados por cores ${ }^{4}$. Enquanto risco os sujeitos poderiam sentir algum desconforto em responder as questões, nesse caso poderiam passar para próxima pergunta ou desistir de participar do estudo. Como beneficio foi possibilitado aos usuários/as indicarem melhorias quanto atendimento, acolhimento e oferta de serviços em saúde para comunidade LGBTQIA+, o que poderá gerar melhorias no atendimento. Considerando que a pesquisa atendeu todas as exigências éticas, foi aprovada por Comitê de Ética universitário conveniado com a Plataforma Brasil. Para retorno aos sujeitos participantes do estudo, foi realizada uma roda de conversa com o intuito de divulgar os resultados e proporcionar espaço de discussão e empoderamento desses sujeitos.

Para análise dos dados foi utilizada análise de conteúdo que consiste em duas funções: verificação de hipóteses ou questões, pois, segundo Minayo (1995), pode-se encontrar respostas para as questões formuladas e também confirmar ou não as afirmações estabelecidas antes do trabalho de investigação. A segunda função refere-se a descoberta do que esta por trás dos conteúdos manifestos, que vai além das aparências do que está sendo apresentado. Dentre os autores que utilizam análise de conteúdo escolheu-se o método de Bardin (2011) que envolve três fases: A primeira é a pré-análise onde se procede à escolha dos documentos, à formulação de hipóteses e à preparação do material para análise. A segunda é a exploração do material, que envolve a escolha das unidades, a enumeração e a classificação. A terceira etapa, por fim, é constituída pelo tratamento, inferência e interpretação dos dados (BARDIM, 2011).

\section{Saúde em uma perspectiva coletiva: concepções e foco}

Preconiza-se que o sistema público de saúde deve ter uma dimensão verdadeiramente universal "quando cobre indistintamente todos os brasileiros com serviços de vigilância sanitária de alimentos e de medicamentos, de vigilância epidemiológica, de sangue, de transplantes de órgãos e outros" (MENDES, 2013, p. 27). Assim - mesmo que por vezes não reconhecido -, as ações do sistema único de saúde se fazem presentes no cotidiano da população por meio de várias ações visando a qualidade de vida da população. Os serviços disponibilizados pelo SUS, ainda devem atuar através da promoção da saúde, educação em

\footnotetext{
${ }^{4}$ As falas dos/as entrevistados/as foram identificadas por cores conforme preconizado junto ao projeto de pesquisa enviado ao CEP aprovado sob o parecer número 3.058.308.
}

Barbarói, Santa Cruz do Sul, n. 58, p.<172-194>, jan/jun 2021 
saúde e prevenção em uma perspectiva de visualizar a saúde não somente no âmbito físico e/ou biológico, mas de forma ampla, o que deveria incluir compreensão sobre os aspectos que envolvem a diversidade sexual dos sujeitos que acessam os serviços de saúde.

Com o objetivo de garantir que o acesso à saúde seja de fato menos excludente, surgiu o conceito "ampliado de saúde", formulado na 8 a Conferência Nacional de Saúde, realizada em Brasília em 1986, fruto da mobilização de diversos movimentos sociais que buscavam combater regimes autoritários e de garantia ao acesso à saúde da população em meio à crise dos sistemas públicos de saúde. A mobilização dos movimentos sociais teve como objetivo a Reforma Sanitária Brasileira (final da década de 1970) caracterizando importante ação de caráter social, materializada posteriormente na carta magna constitucional em 1988. O conceito ampliado de saúde indica que:

\footnotetext{
a saúde é a resultante das condições de alimentação, habitação, educação, renda, meio ambiente, trabalho, transporte, emprego, lazer, liberdade, acesso e posse da terra e acesso aos serviços de saúde. Sendo assim, é principalmente resultado das formas de organização social, de produção, as quais podem gerar grandes desigualdades nos níveis de vida (BRASIL, 1986, p. 4).
}

Tal argumento pode contrapor uma concepção biomédica, baseada na primazia do conhecimento anatomopatológico e na abordagem mecanicista do corpo, cujo modelo assistencial está centrado no indivíduo, na doença, no hospital e no médico. O olhar ampliado em saúde defende intervenções humanizadas multiprofissionais, construída com participação social e que garanta como princípios a universalidade, a integralidade, a equidade, a descentralização, a regionalização. A relevância destas garantias está justamente na explicitação dos determinantes sociais da saúde e da doença, muitas vezes negligenciados nas concepções que privilegiam a abordagem individual, que com relação a organização dos serviços de saúde, ainda parece não estar preparada política e tecnicamente, para repensar suas ações a ponto de adotar medidas concretas de ruptura com o paradigma curativista.

Percebe-se ainda lacunas no atendimento às mais diversas demandas, como por exemplo as barreiras - sejam de ordem técnica e/ou orçamentarias - no ato de atendimento que não garantem o acesso aos serviços. Ainda existe evidente necessidade de fortalecimento de ações de prevenção, promoção e recuperação da saúde individual e coletiva, o que reflete na dimensão social da saúde. A busca pela materialização de uma perspectiva integral da saúde, iniciou essencialmente suas reivindicações com o Movimento da Reforma Sanitária (a partir da década de 1970), na atualidade vem aprofundando suas concepções e metas por meio do viés denominado Saúde Coletiva, complementada por temas como direitos sociais, cidadania e políticas públicas, visando a busca da transformação social da população, uma vez que o meio 
e o modo de vida interferem diretamente nas questões relacionadas a saúde. Assim resumido por Arouca (1987, p. 36) "saúde não é simplesmente não estar doente [...] é um bem estar social, é o direito ao trabalho, a um salário condigno; é direito a ter água, à vestimenta, à educação, e até, a informação sobre como se pode dominar o mundo e transformá-lo".

Por isso, faz-se necessário conhecer os territórios, a população, suas necessidades tanto das instituições quanto dos/as sujeitos para assim identificar possíveis ações para uma intervenção que atenda às necessidades identificadas, pautada em uma política social inclusiva e universalizadora que se afaste de relações interpessoais e espontaneístas. A que se identificar as determinações sociais que impactam no processo saúde e doença para uma efetiva promoção e educação em saúde e prevenção de doenças. Ainda que haja distintas definições de promoção da saúde e prevenção, entende-se que "[...] a promoção da saúde não se dirige a uma determinada doença ou desordem, mas servem para aumentar a saúde e o bem estar [...] a prevenção exige uma ação antecipada" (CZERESNIA, 2003, p. 45).

Neste sentido, torna-se necessário pensar em promover saúde na perspectiva de um atendimento focado em demandas coletivas. Campos (et al, 2004, p. 52) destaca a necessidade da participação democrática visando responder às "[...] necessidades de uma coletividade, mobilizando os setores necessários, envolvendo a população em todo o percurso de produção da saúde, desde o diagnóstico da situação à avaliação das ações implantadas". Para tanto um planejamento participativo com os/as sujeitos e com os/as trabalhadores/as do sistema implica em socializar as informações da gestão sobre o andamento dos programas e serviços, indicadores de serviços pactuados na Comissão Intergestora Bipartite - CIB, indicadores epidemiológicos e fontes orçamentárias.

Implica também em retomar as proposições aprovadas nas Conferências de Saúde e envolver os Conselhos de Saúde Estaduais e Municipais no processo. Destaca-se que a saúde coletiva é caracterizada como um movimento sanitário que inclui a integração de ciências sociais e as políticas de saúde pública identificando demandas importantes de cunho social, econômico e ambiental. A saúde coletiva foca em consequências indesejadas de epidemias e falta de estratégias que atuem na prevenção de situações de risco, buscando ter um olhar ampliado em relação aos sujeitos no sentido de enxergar além da aparência buscando a essência das situações cotidianas. Retoma-se aqui a necessidade de investimento em uma abordagem e acolhimento humanizado que não somente tenha dimensão corporal da doença, mas amplie o olhar a um sujeito que tem uma história, sentimentos, direitos e perspectivas. Existe necessidade de incentivo a participação, com estimulo ao fortalecimento da autonomia desses sujeitos na tomada de decisões em relação a si mesmas e em relação ao meio em que vivem.

Barbarói, Santa Cruz do Sul, n. 58, p.<172-194>, jan/jun 2021 
Faz-se necessário a busca em promover, educar e prevenir temas que historicamente foram negligenciados pelas práticas biomédicas, curativas e individuais como: violência, dependência química, questões de gênero, sexual e etnia, poluição do meio ambiente, saneamento, movimentos sociais na área da saúde mental, direitos reprodutivos, controle social, participação social, etc. Temas que por si só possibilitam aos/as envolvidos tanto profissionais como usuários/as refletir possíveis agravos para busca de formas de abordagens, acolhimentos e atendimentos. Emerge a necessidade de reflexão sobre possíveis leituras preconceituosas, moralistas e higienistas que muitas vezes atrapalham e impedem uma intervenção que poderia contribuir para a transformação da realidade de sobrevivência dos sujeitos e/ou territórios que muitas vezes carregam uma bagagem de elementos históricos, culturais, políticos, etc. que interferem no olhar que se tem sobre o outro, seu modo de vida e consequentemente sob as patologias que o cercam. Dentre os temas de reflexão e intervenção em saúde coletiva, emerge a necessidade de debates em torno da identidade de gênero e identidade sexual para pleno atendimento da diversidade do público que busca atendimento em várias políticas, como a de saúde.

\section{Saúde, Identidade de Gênero e Identidade Sexual}

A identidade de gênero se faz dentro dos contextos sociais e pessoais, desta forma não se apresenta de uma única forma, sendo variável conforme o ambiente em que o sujeito está inserido. Para Hall (2001, p. 7) a crise de identidade é vista como parte de um processo mais amplo de mudança, "que está deslocando as estruturas e processos centrais das sociedades modernas e abalando os quadros de referência que davam aos indivíduos uma coragem estável no mundo social". Neste sentido, conforme o autor não existe uma única identidade estabelecida, mas a forma como os sujeitos buscam por meio de uma construção outras possibilidades de se identificar no mundo apresentando outras configurações de gênero e sexualidade.

Essa noção de identidade deve permear atendimentos, serviços, compreensões e reconhecimento da dignidade humana que acessa políticas públicas como a de saúde, não só voltado ao masculino e feminino, mas um olhar ampliado de várias performances de gênero que podem existir. Não se trata de diferença sexual, mas sim de relação social entre mulheres e homens, homem/homem, mulher/mulher. Porém, na sociedade que insiste em manter o conservadorismo se faz necessário o entendimento que as identidades de gêneros dos sujeitos se constroem no meio social. Scott (1990, p. 14) indica que "o gênero é um elemento 
constitutivo de relações sociais fundadas sobre as diferenças percebidas entre os sexos, e o gênero é um primeiro modo de dar significado às relações de poder".

Nas relações sociais, gênero é entendido como masculino e feminino geralmente é concebido como algo natural ao nascimento, porém nem sempre é entendido como a condição que o sujeito se identifica e que não é ligado a características anatômicas e fisiológicas. No entanto, no meio social as identidades não são fixas e nem pré-determinadas e sim constantemente modificadas (HALL, 2006). Afirma-se que o gênero "institui a identidade do sujeito, pretende-se referir, portanto, a algo que transcende o mero desempenho de papéis, a ideia é perceber o gênero fazendo parte do sujeito, constituindo-o" (LOURO, 2010, p. 25). Portanto, gênero não se resume ao estabelecido quanto às características impostas ao masculino e feminino, mas, configura-se em um processo de construção dos sujeitos que nem sempre está de acordo com o sexo biológico ou com a genitália da pessoa. Já orientação sexual refere-se a atração afetivo sexual por alguém sem estabelecer gênero, mas constituído internamente.

\footnotetext{
a sexualidade pode ser mais bem compreendida como junção (sobreposta) do biológico, das crenças, das ideologias, dos desejos, dos afetos, das manifestações e práticas sexuais, fatores esses amplamente configurados por aspectos sociais e culturais. Sendo assim, a sexualidade não pode ser caracterizada apenas pela "possível” relação entre sexo biológico, identidade de gênero e orientação do desejo afetivo-erótico-sexual (PRADO, 2010, p. 409).
}

Igualmente, dentro dessa mesma lógica, está a cisnormatividade, a qual parte do pressuposto de que toda pessoa é cissexual, ou seja, aquelas pessoas que são assignadas com o sexo feminino ao nascer sempre tornam-se mulheres e aquelas assignadas com o sexo masculino, homens (BAUER, et al, 2009). Neste sentido ao falar de orientação sexual assim como identidade de gênero entende-se que é um processo de construção estabelecido pelo próprio sujeito podendo se transformar em plural não se configurando em uma única orientação (heterossexual, homossexual, bissexual, etc.).

Do mesmo modo que a heteronormatividade, a cisnormatividade molda a organização social e cria resistência à existência de outras formas de identidades/expressões de gênero. A construção deste termo visa, entre outras coisas, visibilizar o privilegio e legitimidade dado às pessoas que não seguem os padrões pré-estabelecido pela sociedade (SERANO, 2007). Pode se dizer que estes paradigmas não só oprimem à pessoa chamada "desviante", mas também, aquelas que são produto deste e/ou que estão alienados ao sistema como verdade única, uma vez que condicionam à sua existência a parâmetros herméticos, pouco ou nada refutáveis.

Em meio aos mais diferentes preconceitos, cabe destacar importante resistência exercida por meio dos movimentos LGBTQIA+ que começam no Brasil, surgir a partir da segunda metade dos anos 1970, junto a organizações do movimento negro contemporâneo, como o Barbarói, Santa Cruz do Sul, n. 58, p.<172-194>, jan/jun 2021 
Movimento Negro Unificado e o Movimento Homossexual, como o Somos - Grupo de Afirmação Homossexual, de São Paulo. O nascimento do movimento homossexual no Brasil é marcado pela afirmação de um projeto de politização da questão da homossexualidade em contraste às alternativas presentes no "gueto" e em algumas associações existentes no período anterior ao seu surgimento. O movimento - antigamente chamado LGBT - foi organizado pela sociedade civil configurado em diferentes tipos de identidade sexuais e de gênero, as quais compreendiam entre elas: Lésbicas, Gays, Bissexuais, Travestis, Transexuais e Transgêneros. Este movimento organizado por diferentes sujeitos políticos em seus coletivos ainda demanda por igualdade de direitos sociais, reconhecimento, respeito, por meio da visibilidade, da transformação social e de ações contra a discriminação e a violência.

Em 2008, a Secretaria Especial de Direitos Humanos da Presidência da República realizou a I Conferência Nacional de Lésbicas, Gays, Bissexuais, Travestis e Transexuais promovendo intensa mobilização de governo e da sociedade civil, tanto nas 27 conferências estaduais, como na etapa nacional que reuniu mais de 600 delegados (BRASIL, 2013, p. 12).

Como forma de buscar fortalecer e dar atenção ao movimento o Estado trouxe para discussão princípios da política LGBTQIA+ na intenção de legitimá-los e fortalecer a necessidade de trazer como pauta a visibilidade e a participação do referido público junto ao controle social para formulação de políticas públicas que reforcem os direitos deste segmento na sociedade, inclusive no âmbito da saúde. Os movimentos em torno da pauta LGBTQIA+ dentre várias bandeiras de luta, indica a necessidade de despatologização da homossexualidade por legislação antidiscriminatória. Reflete sobre a necessidade de reconhecimento de que a discriminação por orientação sexual e por identidade de gênero incide na determinação social da saúde, no processo de sofrimento e adoecimento decorrente do preconceito e do estigma social a que está exposta a população de lésbicas, gays, bissexuais, travestis, transexuais e transgêneros.

No âmbito da saúde, foi instituída pela Portaria $n^{\circ} 2.836$ de $1^{\circ}$ de dezembro de 2011 a Política Nacional de Saúde Integral de Lésbicas, Gays, Bissexuais, Travestis, Transgêneros e Transexuais (LGBTTT) que tem por objetivo promover a saúde integral LGBTQIA+ eliminando a discriminação e o preconceito institucional. Bem como para contribuir para a redução das desigualdades e a consolidação do SUS como sistema universal, integral e equitativo. Para sua efetivação traz em alguns dos seus princípios propostas a seguir:

II - contribuição para a promoção da cidadania e da inclusão da população LGBT por meio da articulação com as diversas políticas sociais, de educação, trabalho, segurança; III - inclusão da diversidade populacional nos processos de formulação, implementação de outras políticas e programas voltados para grupos específicos no SUS, envolvendo orientação sexual, identidade de gênero, ciclos de vida, raça-etnia e território; VIII - produção de conhecimentos científicos e tecnológicos visando à Barbarói, Santa Cruz do Sul, n. 58, p.<172-194>, jan/jun 2021 
melhoria da condição de saúde da população LGBT; e IX - fortalecimento da representação do movimento social organizado da população LGBT nos Conselhos de Saúde, Conferências e demais instâncias de participação social (BRASIL, 2011, s.p. 22).

A politica nacional de saúde integral LGBTQIA+ expressa não somente o direito a saúde, mas todo um contexto de respeito a dignidade humana via politicas intersetoriais, fomento a processos socioeducativos, bem como fortalecimento de controle social e atendimento especializado. Pergunta-se então, por qual motivo vivencia-se tanta discriminação e as mais variadas formas de violência e invisibilidade quanto acesso aos serviços de saúde? Nesse sentido, debate-se agora sobre os caminhos por onde andam os atendimentos em saúde dispensados ao público LGBTQIA+ a partir do estudo realizado.

\section{A (in) visibilidade do acolhimento ao público LGBTQIA+ no âmbito da saúde}

A partir das reflexões tecidas até o momento, apresenta-se nesse subitem os resultados da pesquisa realizada a partir do olhar dos sujeitos entrevistados/as. Participaram do estudo onze sujeitos que responderam por meio de entrevista a um formulário com perguntas abertas e fechadas. A faixa etária dos participantes variou em torno de 24 anos sendo que o mais novo tem 18 anos e o mais velho tem 49 anos, percebeu-se que a maioria encontra-se na informalidade, portanto em trabalhos precarizados, mantendo em sua maioria o sustento básico da residência. Quanto a renda em média recebem em torno de dois salários-mínimos que varia conforme a produção mensal da atividade desenvolvida, sendo que o menores salários giraram em torno de 50,00 a 600,00 reais e o maior foi de 2.000,00 mil reais. Neste público a média de escolaridade prevalece no ensino médio incompleto, alguns inclusive somente com ensino fundamental. Ficou constatado que o acesso à educação ainda tem se constituído um desafio, pois alguns relatam que interromperam os estudos para trabalhar ou por não resistir ao ambiente familiar e escolar que se apresentou opressor e preconceituoso.

Ainda buscou-se dar visibilidade quanto a compreensão e/ou identificação que os/as entrevistados/as se atribuem. Quanto a identidade de gênero, quatro das pessoas entrevistadas se auto identificaram como homens cis, quatro como mulheres cis, duas como mulheres trans e uma como travesti, o que indica uma diversidade de identificação de gênero, que merece ser respeita e compreendida para que possa de dialogar com os/as mesmos/as de forma interativa. Já quanto a identidade sexual, duas pessoas se auto identificaram como pansexual, uma como lésbica, quatro como bissexual e quatro com gays. Chamou atenção o termo pansexual ainda pouco utilizado, porém já escolhido pelos/as entrevistados/as como sendo um sujeito que não tem um desejo definido específico, não se limitam apenas ao gênero masculino ou feminino, 
mas são interessados/as em todos os diferentes tipos de sexualidades, como por exemplo os intersexuais (pessoas que se identificam com os dois gêneros: masculino e feminino). Em suma, os pansexuais sentem atração por todos os gêneros sexuais existentes, sem distinção não se limitando a binária de gênero homem - mulher.

Foi questionado aos/as participantes quanto a forma de acesso aos serviços de saúde, mais da metade, oito pessoas, respondeu que o acesso aos serviços de saúde ocorre segundo duas possibilidades, via SUS e via atendimento privado. O motivo pela procura pelo o acesso a saúde em ambas as possibilidades foi indicado levando em conta a falta de um serviço especializado que garanta um tratamento adequando as necessidades desses sujeitos como podemos perceber na fala da participante Vermelho:

\begin{abstract}
procurei algumas vezes o posto de saúde perto da minha casa para iniciar um tratamento de hormonioterapia, lá além de não acessar o tratamento, não recebi nenhum tipo de orientação de como proceder e onde chegar, além de que quando a pessoa chega no postinho tu já percebe que todos os olhares estão focados em ti, a pessoa que está na recepção nem ao menos te olha nos olhos, não tem quem aguente tamanha indiferença, e digo isso não porque é público e que o privado seja melhor, já passei por situações parecidas no privado também, e mesmo com minhas limitações financeiras por enquanto para o meu tratamento procuro a rede privada que acaba me orientando, me ouvindo e garantindo ainda que pago o acesso a um tratamento.
\end{abstract}

Assim, o afastamento do serviço de saúde pode ser gerado tanto pela falta de um atendimento especializado quanto pelo acolhimento estigmatizado e em muitas situações opressor, ainda justificado pela falta de conhecimento, crenças, preconceitos, etc.. Nas falas a seguir, percebe-se que o estigma do HIV/AIDS conhecida nos anos de 1980 como a "peste gay" e que por muito tempo foi atribuído aos gays ainda é muito presente. Os participantes foram unânimes em trazer relatos referentes ao acolhimento logo direcionado ao teste rápido independe do objetivo da procura ou tratamento ao serviço de saúde, sendo assim se pressupõe que todo o membro de comunidade LGBTQIA+ tem a doença. Como pode-se observar a seguir a referida postura acaba provocando um atravessamento logo no acolhimento dos serviços o que na concepção dos/as entrevistados/as prejudica o cotidiano de intervenções no âmbito da saúde a partir de várias formas de preconceito:

o acolhimento é logo voltado ao HIV, as doenças (LILAS).

no acolhimento não existe respeito com relação a orientação sexual, o atendimento é frio e julgador da parte de alguns profissionais [...] Eu mesma muitas vezes procurei aguentar até as últimas consequências de dores em casa antes de ir procurar o postinho porque sabia que talvez voltaria mais doente quando voltasse para casa já sabendo como seria o tratamento em relação a mim (MARRON).

existe um preconceito nos olhares julgadores, nos cochichos, acredito que é falta de respeito, é um preconceito velado (AMARELO). 
Parte-se do pressuposto que esse segmento evita procurar os serviços públicos de saúde por acreditarem que serão discriminadas/os e não terão suas necessidades específicas e gerais atendidas. Outro fator tem relação as/os profissionais de saúde, sobretudo na relação médico-paciente baseando suas ações em uma premissa da hetero-cisnormatividade, não se capacitando e/ou não sendo capacitadas/os, para a atenção à complexidade das questões de saúde demandas pela população LGBQIA+, em especial, das/os transgênero, transexuais e travestis (Trans). Conforme os relatos dos/das participantes, identifica-se que muitos usuários/as do sistema de saúde são submetidos a atitudes preconceituosas e discriminatórias, operando como elementos de perpetuação dos estigmas em torno dessa população.

\begin{abstract}
já passei por situações péssimas onde eu menos esperava passar que era na saúde quando fui procurar tratamento para uma alergia que surgiu nas minhas partes íntimas e o médico pediu para que eu ficasse totalmente nua, ele nem sequer examinou mandou que eu me vestisse e mandou eu fazer o teste rápido, deu negativo para as doenças, mandou eu usar uma pomada e disse que eu retornasse lá, retornei depois de um tempo, ele então mandou que eu fizesse o teste rápido novamente [...] já precisei retornar lá com o mesmo médico outras duas vezes e as mesmas duas vezes ele mandou eu fazer o teste rápido e eu já imaginando que ele iria pedi já ia com os testes anteriores na bolsa mas ele sempre dizia que aqueles não tinham mais validade. Estar na frente dele para mim era sempre desconfortável, porque tenho um relacionamento com meu namorado de alguns anos já e ele mesmo nunca tinha me visto nua na luz e ter de ficar naquela situação na frente de um estranho mesmo sendo um médico e ainda ser tratada com desprezo como foi feito me abalou muito (MARRON).
\end{abstract}

$\mathrm{Na}$ fala anterior percebe-se nitidamente a presença de uma ação profissional de total desprezo com ações estigmatizadas onde se rotulou a usuária a partir de imaginário social de que toda a pessoa inserida em um contexto LGBTQIA+ mantem uma vida social considerada “promiscua". O profissional não demostra consideração para com a usuária, não possibilita diálogo, não pede mais informações para aprofundar as causas do problema e estigmatiza a enfermidade que a mesma apresenta. Na fala a seguir é possível identificar outra ação profissional negligenciada e de desinformação:

para mim foram dois momentos muito ruins quando fui procurar o serviço de saúde, um deles foi quando fui fazer uma consulta ginecológica, falei espontaneamente minha orientação sexual por entender que isso seja normal e seria importante a médica saber já que desde minha entrada não havia sido perguntado, a profissional me disse que eu não precisava consultar já que não tinha relações sexuais com homens, eu fiquei pasma e pensei na hora o que faço agora, fico sentada na frene dela esperando para ver o que ela vai dizer ou levanto e saio? (LARANJA).

Diante destes dois relatos, confirma-se o distanciamento do público LGBTQIA+ dos serviços de saúde, levando em conta a forma como são tratados pelos/as profissionais. Ações estas que contribuem para o agravamento de situações de saúde causados pelo medo do constrangimento, da violência institucional e violência de gênero que causam sérios danos a 
vida desses sujeitos que já carregam uma carga nata de exclusões ocasionadas em muitos casos no ambiente familiar, escolar, no trabalho, etc.. Estas experiências discriminatórias no SUS e/ou nos serviços particulares de violência simbólica e/ou dentro da hetero-cis-normatividade podem estimular os/as usuários/as a automedicação e a procura de produtos e serviços clandestinos que resultam em situações complicadas e põem em risco a vida dessas pessoas, além de que vão contra ao princípio da Política Nacional de Saúde Integral LGBTQIA+ (2011) que indica:

I - respeito aos direitos humanos LGBT contribuindo para a eliminação do estigma e da discriminação decorrentes das homofobias, como a lesbofobia, gayfobia, bifobia, travestifobia e transfobia, consideradas na determinação social de sofrimento e de doença (BRASIL, 2011, s.p. 22).

A mesma política prevê atenção integral, capacitações para equipe e trabalhadores dos diferentes serviços do SUS, que devem se manter atualizados e cientes das políticas públicas existentes na atenção à população LGBTQIA+, assim como dos demais princípios de inclusão existentes. É também fundamental uma educação continuada, enquanto ferramenta indispensável dos sistemas de saúde para assegurar a qualidade e pertinência das ações para a atenção às necessidades em saúde.

\section{Possibilidades de intervenção no âmbito da saúde coletiva para comunidade LGBTTT}

Foi questionado aos/as entrevistados/as se acreditam que há necessidade de atendimento ou serviços específicos no âmbito da saúde aos membros da comunidade LGBTQIA+, onde sete pessoas entrevistadas/as responderam que não deveria ter um serviço específico, mas que os/as profissionais deveriam ser capacitados para entender a dinâmica e os processos de mudanças, assim como terem a consciência de que estão trabalhando com pessoas e por esse motivo é necessário acolhimento humanizado, que se tenha escuta e olhar para quem chega até o serviço sinta-se respeitado. A justificativa para que não se tenha um serviço específico vem no sentido de amenizar o estigma social que esse público enfrenta e que por muitas vezes os afasta de procurar o atendimento de saúde para evitar constrangimentos ligados a imagem/aparência, as IST's (Infecções Sexualmente Transmissíveis) e ao nome social que por muitas vezes o profissional que atende apresenta-se resistente em utilizar-se deste direito amparando-se na burocracia. Embora exista a necessidade e garantia de serviços específicos alguns sujeitos encararam que não deveria ter um serviço exclusivo na perspectiva de não gerar mais exclusão, podendo ainda reforçar a culpabilização dos sujeitos.

Já quatro pessoas entrevistadas/os responderam que sim, que é necessário um atendimento especifico ao público LGBTQIA+ com profissionais capacitados, acreditam que 
assim o acesso seria maior por entenderem que não haveriam julgamentos uma vez que os/as profissionais já teriam entendimento que trata-se de um serviço diferenciado. Nesse sentido, não há uma unanimidade quanto ao fato de ter serviços de saúde específicos ou não para atendimento aos LGBTQIA+, porém é fato que independente da forma de acesso todos/as querem sentir-se respeitados, tendo suas demandas atendidas com qualidade de forma equitativa.

Quando indagados/as quanto que possibilidades de melhorias no atendimento poderiam ser buscadas no âmbito da saúde nove entrevistados/as trouxeram a importância do acolhimento humanizado, da informação e da capacitação dos/as profissionais acerca do tema gênero, sexualidade e saúde LGBTQIA+:

\begin{abstract}
assim como é necessário melhorias no serviço de saúde no geral é necessário também um olhar capacitado quando se tem a procura de alguém que não está feliz com a identidade que lhe é atribuída e que neste sentido precisa de um olhar e de um atendimento especializado mais acolhedor para se auxiliar neste processo, mas que mesmo tendo essa consciência de que é necessário essas melhorias não saberia que tipo de sugestão oferecer (LILÁS).

é necessário capacitações, palestras, cursos de conscientização de que não somos monstros, aberrações, pecadores e nem desviados de um processo da natureza humana, somos pessoas que também temos sentimentos, sonhamos em ter uma família, amamos e somos amados, participamos da evolução das coisas e da progressão da sociedade pagamos também nossos impostos e contribuímos em muitas coisas com nossas ideias, temos profissão ajudamos no desenvolvimento social da sociedade e queremos ser vistos como tais, um exemplo de melhorias é essa tua pesquisa que nos dá a oportunidade de ter voz, expressar o que queremos, nos tira da margem, porque não somos a minoria, somos a maioria (AMARELO).
\end{abstract}

Ideias, crenças explícitas e implícitas, contextos socioculturais e a falta de um diálogo entre profissionais e usuários/as dificultam e impedem, um olhar atento e uma escuta sensível e qualificada, necessárias para que se tenha êxito no acompanhamento e eficácia nas ações resolutivas dos serviços prestados. A Política Nacional de Atenção Integral a saúde LGBTTT (BRASIL, 2011) em seu artigo quarto, preconiza eliminação das homofobias e demais formas de discriminação que geram a violência contra a população LGBTQIA+. Ainda no princípio quinto destaca-se a implementação de ações, serviços e procedimentos no SUS, com vistas ao alívio do sofrimento, dor e adoecimento relacionados aos aspectos de inadequação de identidade, corporal e psíquica relativos às pessoas transexuais e travestis. Para isso é preciso abertura e sensibilidade humana para aceitar o que não é igual a si ou que não segue aquilo que se pensa ser o certo.

os profissionais precisam entender que as coisas evoluem, mudam e junto com essas mudanças a forma de atender e tratar com as pessoas também, na verdade desde que o mundo é mundo sempre existiram pessoas que não se conformavam com aquilo que lhes era imposto, só que antigamente essas pessoas eram tratadas como doentes, loucas e excluídas da sociedade [...] a pouco tempo fui por conta própria buscar 
auxílio de uma psicóloga porque estava passando por algumas dificuldades de convivência com a minha mãe, durante a consulta a psicóloga fez várias perguntas e não sei como chegou na pergunta sobre minha orientação eu falei tranquilamente disse que minha mãe não sabia. Ela então pediu para que a próxima consulta fosse com minha mãe, quando cheguei na próxima consulta ela nem se quer falou mais comigo e falava somente com a minha mãe e disse que iria me encaminhar para um psiquiatra, fui ao psiquiatra ele nem se quer deixava eu falar muita e ainda disse para ela que eu estava passando por uma fase de rebeldia e que isso iria passar com um tempo que era só uma fase. No fim os dois profissionais não me auxiliaram em nada e ainda me faziam pensar que o problema era comigo em função da minha orientação sexual (VERDE).

Como consequência de determinadas ações, podem ser gerados traumas ocasionados por constrangimentos, frieza e indiferença no acolhimento ou consulta que podem levar ao afastamento antes mesmo de se criar vinculo, não raro levando a desistência de possíveis ou futuras procuras criando assim barreiras e desconfiança da equipe do serviço de saúde. Para Marx (1989); o homem na sociedade capitalista vive conflitos que emergem das relações de opressão criadas por um modelo excludente e castrador das vontades e desejos de criação e expressão livre. Nesse sentido, vários problemas diagnosticados como desajustes de conduta social são classificados desse modo para criar modelos de comportamento aceitáveis socialmente. A opção de fuga cria estereótipos, preconceitos e instituições que vêm domesticar os “corpos desajustados" socialmente. Ressalta-se novamente, que esses conflitos se ocasionam os distanciamentos que podem prejudicar ações tanto da aproximação e acesso dos/as usuários/as aos serviços de saúde quanto a uma possível aproximação da equipe de saúde da família no domicílio dos mesmos.

O acesso limitado e fragilizado na busca de uma orientação e/ou auxílio as necessidades relacionadas a orientação sexual ficam fragilizadas quando não há a garantia tanto de um serviço especializado quanto um profissional ou equipe que acolha, entenda e participe junto do processo de amenização do sofrimento de quem busca ser entendido em meio a um processo de adoecimento que atingi tanto a saúde física quanto mental. Destaca-se que os/as entrevistados/as reconhecem que necessitam de atendimento:

sim a psicologia, a psicanalise iria facilitar muito o acesso das pessoas trans para hormonioterapia, cirurgia de resignação sexual por que iria amenizar o sofrimento que vem da família. Tem gente que tem dificuldade de reconhecimento pela imposição da heteronormatividade a exaltação do falo e o desprezo da vagina (ROXO).

Existe necessidade de compreensão sobre o fato das relações de gênero sobreporem um gênero sobre o outro como o masculino sobre o feminino, nessa sobreposição visualiza-se uma pirâmide de privilégios onde o homem cis em uma sociedade machista é privilegiado em relação a mulher cis e estes em relação aos homens homossexuais que por sua vez acabam por ter 
privilégios em relação a lésbicas e estas categorias em relação a pessoas Trans e Travestis em uma situação de privilégios acabam ficando a margem da sociedade.

é necessário ter projetos de inclusão, que trabalhem o respeito as diferenças e que isso contribua com o tratamento que for buscado e não que atrapalhe mais, não precisa nem ser pessoas LGBT's para realizarem esse tipo de projeto, mas que respeitem, sejam mais humanos e não tenham preconceito (LILAS).

Projetos de inclusão que trabalhem o respeito as diferenças também são preconizados na Política Nacional de Atenção Integral a Saúde LGBTQIA+ (2011, p. 8 ) onde destaca-se a necessidade de "inclusão da temática da orientação sexual e identidade de gênero de lésbicas, gays, bissexuais, travestis e transexuais nos processos de educação permanente desenvolvidos pelo SUS, incluindo os trabalhadores da saúde, Conselhos de Saúde e as lideranças sociais”.

A capacitação como forma de levar informações aos/as trabalhadores/as, as escolas, aos grupos sociais, empresas, etc. é mais que necessária no intuito de contribuir e amenizar situações de violência e constrangimento que levam a exclusão. De nada adianta exigir atenção integral e qualificada se temas como Orientação Sexual e Identidade de Gênero, Nome Social e tratamento especializado as demandas da população LGBTQIA+ não forem apresentadas e debatidas conforme preconiza a $6^{\mathrm{a}}$ Diretriz da Política Nacional de Atenção Integral a saúde LGBTQIA+ que indica a necessidade de "difusão das informações pertinentes ao acesso, à qualidade da atenção e às ações para o enfrentamento da discriminação, em todos os níveis de gestão do SUS" (BRASIL, 2011, p. 23).

O medo imposto no meio familiar e nos círculos sociais contribuem para silêncio e sofrimento solitário, os sujeitos acabam guardando para si seus medos, suas denúncias, seus constrangimentos e acabam se tornando vítimas de um sistema opressor hetero-cis normativo que induz essa população e se perceberem como pessoas doentes ou problemáticas, com confusões mentais e causadoras dos problemas que vivenciam. A participante a seguir quando questionada se tomou alguma atitude em relação a situação de violência que sofreu no atendimento psicológico respondeu: "não porque meus pais não sabiam da minha orientação sexual, então de alguma forma pensei que as coisas poderiam piorar" ( LILAS). Outra forma de violência que o público LGBTQIA acaba sofrendo ao buscar o serviço de saúde é a forma depreciativa e desinteressada que é dada a diversidade, essas ações repercutem na qualidade de vida destas pessoas, na sua autoestima e viola seus direitos e liberdades.

\footnotetext{
uma vez fui consultar no postinho do meu bairro, faço uso do nome social mas na hora de ser chamada para o atendimento fui chamada pelo nome do finado, senti um frio na barriga e fiquei sem reação, esperei um pouco mais e fiz que não era comigo, fui embora para casa sem ser atendida. Quando cheguei em casa me senti a pior das pessoas por não ter levantado e feito um barraco na hora que a atendente chamou pelo outro nome (ROXO).
} 
Assim, o acolhimento é a porta de entrada dos serviços de saúde, vai depender dele a continuidade e efetivação do que se pretende buscar. Faz parte do acolhimento humanizado o respeito pelo nome social e o uso adequado dos pronomes por parte das/os profissionais e trabalhadoras/os da saúde. O seu uso é de suma importância na relação e empatia destas pessoas com a equipe e para a criação do vínculo que é de extrema necessidade e que vai pautar a saúde da pessoa que está procurando ser atendidas, assim como a sua adesão às futuras orientações, terapias, procedimentos, etc. Ficou claro na fala do/as entrevistas/os que não se quer muito em termos de melhoria, uma vez que foi indicado, que o respeito a opções de cada um já seria um avanço. Ficou claro a necessidade de contextos que possibilitem diálogos, projetos socioeducativos e mais do que nunca respeito a dignidade e autonomia do ser enquanto sujeitos detentores de direitos.

\section{Notas Finais}

Diante desta pesquisa, fica constatado que os serviços de saúde ainda não possuem estrutura e/ou profissionais capacitados para trabalhar a diversidade sexual no seu todo. Sendo assim, respondendo ao problema de pesquisa do estudo, constatou-se que a medida que o serviço oferecido não é qualificado em relação as demandas recorrentes a identidade de gênero e orientação sexual, nem respeita as garantias constitucionais, está sim (in) visibilizando o atendimento que deveria ser garantido. Marginalizados/as o púbico LGBTQIA+ sofre consequências que incidem sobre seu bem-estar social, o que influi de forma positiva ou negativa em sua saúde integral.

Existem barreiras em relação ao acesso da população LGBTQIA+ na busca por um atendimento de saúde sendo o acolhimento o momento mais prejudicado na interação entre os serviços prisionais e usuários/as. O acolhimento quando ocorre é estigmatizado e opressor quando, por exemplo, pressupõe que todos tem HIV ou ainda quando prevê que todos/as devem ser heteros - causando (in) visibilidade no atendimento quanto as necessidades e particularidades desse público, gerando assim violência institucional norteada pela discriminação, ou seja, LGBTQIAFobia - preconceito profissional e institucional que contribui para o aumento das desigualdades vindo a refletir na não consolidação do SUS enquanto sistema universal, integral e equitativo -.

Essa LGBTQIAfobia pode ser observada na ineficiência de um olhar humanizado, agravado pela falta de compreensão quanto a diversidade presente dentro da população LGBTQIA+, que apresentam demandas, que variam para lésbicas, gays, bissexuais, travestis, transexuais e transgêneros. A LGBTQIAfobia pode estar sendo perpetuada pela falta de Barbarói, Santa Cruz do Sul, n. 58, p.<172-194>, jan/jun 2021 
capacitação e despreparo dos profissionais de saúde que se manifesta em ciclos de violência, como a dificuldades em ter garantido um atendimento em saúde humanizado, equitativo e integral, além de encontrar dificuldades, que causam sofrimento e constrangimentos diversos, o que impede que demandas particulares e específicas sejam atendidas, entre elas, por exemplo, a garantia de uso do nome social de travestis e transexuais, a prevenção de novos casos de cânceres ginecológicos (cérvico uterino e de mamas) entre lésbicas e mulheres bissexuais e também de novos casos de câncer de próstata entre gays, homens bissexuais, travestis e transexuais, bem como ampliar o acesso aos tratamentos dessas doenças.

Quanto às indicações de melhorias no atendimento ao público LGBTQIA+, embora seja ressaltada a necessidade de serviço especializado, paira importante posicionamento, não unanime, quanto ao fato que um serviço exclusivo para esse segmento poderia gerar reprodução de exclusões e rótulos. Independente de posicionamentos existe indicação geral quanto à necessidade de melhoria no acolhimento humanizado, da informação e da capacitação dos/as profissionais acerca do tema gênero, sexualidade e saúde LGBTQIA+. Ainda foi pontuada a necessidade de inclusão da temática orientação sexual e identidade de gênero de forma geral na sociedade seja nas escolas, órgãos de categorias profissionais, conselhos e demais instituições públicas e privadas para que se crie a cultura de respeito a diversidade.

A que se ressaltar que não existe uma única identidade estabelecida, mas a forma como os sujeitos buscam por meio de uma construção outras possibilidades de se identificar no mundo apresentando outras configurações de gênero e sexualidade. Crenças explícitas e implícitas, contextos socioculturais conservadores e a falta de um diálogo entre profissionais e usuários/as foi demarcado como algo que dificulta e impedem, um olhar atento e uma escuta sensível. Assim quando não se tem habilidade ou compreensão sobre determinado contexto de atendimento se (in) visibiliza o diferente, o que inquieta, o que pressupõe a mudança de postura e alteridade para com aqueles/as que destoam do sistema vigente. Reforçasse a necessidades de estudo que deem visibilidade a necessidade de garantia de atendimento integral a saúde que leve em conta o direito de todos/as.

\title{
THE (IN) VISIBILITY OF WELCOME IN THE HEALTH SCOPE: THE EXPERIENCES OF MEMBERS OF THE LGBTQIA + COMMUNITY
}

\begin{abstract}
This article presents results of research that sought to investigate how health services can (in) make the service to the LGBTQIA + public visible. The theme becomes relevant as it discusses the need for qualified reception as well as its implication in the lives of lesbians, gays, bisexuals, transvestites, transsexuals and transgender people who seek access to health services and who
\end{abstract}


in some way may end up suffering some type of violence - not always intentional - professional or institutional. Qualitative research was carried out via an intentional sample, where interviews were conducted with eleven members of the LGBTQIA + community. The data were analyzed via content analysis in the light of the critical dialectical method. From the data collected and reflections generated, it is evident that actions characterized as LGBTQIAphobia occur daily. Not infrequently, prejudiced questions persist and disrespect for human dignity. It is evident, the need for training, dialogues and respect for legislation that reduce health care in an expanded way.

Keywords: Collective Health; LGBTQIA +; Reception.

\section{REFERÊNCIAS}

AROUCA, A. S. S. Democracia é saúde. In: 8 a Conferência Nacional de Saúde, 1986,

Brasília. Anais. Brasília: Centro de Documentação do Ministério da Saúde, 1987. p. 35-42.

BARDIN, L. Análise de conteúdo. São Paulo: Edições 70, 2011.

BAUER, G. R.; HAMMOND, R.; TRAVERS, R.; KAAY, M.; HOHENADEL, K. M.; BOYCE, M. "I Don't Think This Is Theoretical; This Is Our Lives": How Erasure Impacts Health Care for Transgender People. Journal of The Association of

Nurses in Aids Care, v. 20, n. 5, p.348-361, 2009.

BECKER, H. Métodos de pesquisa em ciências sociais. São Paulo: Hucitec, 1993.

BRASIL. Ministério da Saúde. Secretaria de Gestão Estratégica e Participativa. Departamento de Apoio à Gestão Participativa. Política Nacional de Saúde Integral de Lésbicas, Gays, Bissexuais, Travestis e Transexuais / Ministério da Saúde, Secretaria de Gestão Estratégica e Participativa, Departamento de Apoio à Gestão Participativa. Brasília: 1. ed. Ministério da Saúde, 2013.

BRASIL. Constituição (1988). Constituição da República Federativa do Brasil. Brasília, DF: Senado Federal, 1988.

BRASIL. Relatório Final de $8^{\text {a }}$ Conferência Nacional de Saúde (1986)

http://bvsms.saude.gov.br/bvs/publicacoes/8_conferencia_nacional_saude_relatorio_final.pdf. Acesso em 10 de fevereiro de 2018.

BRASIL. Anais da Conferência Nacional de Gays, Lésbicas, Bissexuais, Travestis, transgêneros e Transexuais - Direitos humanos e políticas públicas: o caminho para garantir a cidadania GLBT; 5 a 8 de junho de 2008. Brasília, DF.

BRASIL. Secretaria de Direitos Humanos da Presidência da República. Política Nacional de Humanização, Brasília, 2010.

CAMPOS, G. W.; BARROS R. B.; CASTRO A. M. Avaliação de política nacional de promoção de saúde. Revista Ciências e Saúde Coletiva, Rio de Janeiro, vol.9, n.3, p.745-749, 2004.

CARDOSO, M. R.; FERRO, L. F. Saúde e População LGBT: Demandas e Especificidades em Questão. Revista Psicologia: Ciência e Profissão, Brasília, v. 32, n.3, p.552-563, 2012. 
CZERESNIA, D. Promoção da saúde: conceitos, reflexões, tendências. Rio de Janeiro: Editora Fiocruz, 2003.

GIL, A. C. Como elaborar projetos de pesquisa. 4.ed. São Paulo: Atlas, 2002.

HALL, S. A identidade cultural na pós-modernidade. Rio de Janeiro: DP\&A Editora, 2006.

LOURO, G. L. O Corpo Educado: Pedagogias da Sexualidade. Minas Gerais: Editora Autêntica, 2010.

MARTINELLI, M. L. Pesquisa qualitativa: um instigante desafio. São Paulo: Veras, 1999.

MARX, K. O capital: crítica da economia política. Rio de Janeiro: Civilização

Brasileira, 1980.

MARX, K. Contribuição para a crítica da economia política. São Paulo: Mandacaru, 1989.

MENDES, E. V. 25 anos do Sistema Único de Saúde: resultados e desafios - As redes de atenção à saúde. Revista Estudos Avançados, São Paulo, vol.27 no.78, p. 27-34, 2013.

MINAYO, M. C. S. O Desafio do Conhecimento: pesquisa qualitativa em saúde. São Paulo, Rio de Janeiro: HUCITEC/ABRASCO, 1995.

PESSÔA, E. M. Assistência Social ao idoso enquanto direito de proteção social em municípios do Rio Grande do Sul. Porto Alegre. 196 f. [Tese de Doutorado], PUCRS, 2010.

PRADO. V. M. Sexualidade (S) em cena: as contribuições do discurso audiovisual para a problematização das diferenças nos espaços escolares. 2010. 157 f. [Dissertação de Mestrado], Curso de Pós-Graduação em Educação, Universidade Estadual Paulista, Presidente Prudente, Brasil, 2010.

SCOTT, J. Gênero: uma categoria útil de análise histórica. Revista Educação e Realidade, Porto Alegre, v.16, n.2, p., 5-22, jul/dez., 1990.

SERANO, J. Whipping Girl: A Transsexual Woman on Sexism and the Scapegoating of Femininity. Berkeley, Ca: Seal Press, 2007. $408 \mathrm{p}$.

Data de recebimento: $12 / 02 / 2020$

Data de aceite: $11 / 10 / 2020$

\section{Sobre os autores:}

Nizar Amin Shihaded é graduado em Serviço Social pela Universidade Federal do PAMPA, Especialista em Saúde Coletiva pelo Programa de Residência Integrada Multiprofissional em Saúde Coletiva da UNIPAMPA. Mestrando no curso de Mestrado em Serviço Social - área de concentração: Serviço Social, Direitos Humanos e Questão Social da Universidade Federal de Santa Catarina. Endereço Eletrônico: nizdu@hotmail.com 
Elisângela Maia Pessoa é graduada, Mestre e Doutora em Serviço Social. Pós-doutora em Antropologia. Professora Associada do Curso de Serviço Social da Universidade Federal do Pampa - Campus São Borja. Integrante do Grupo de pesquisa em Políticas Sociais, Questão Social e Relações de Exploração/Opressão. Endereço Eletrônico: elisangelamaiapessoa@gmail.com

Fabiane Ferreira da Silva é graduada em Química Licenciatura/Habilitação Ciências, mestra e doutora em Educação em Ciências. Professora associada da Universidade Federal do Pampa Campus Uruguaiana. Atua no Curso de Ciências da Natureza - Licenciatura e no Programa de Pós-Graduação em Educação em Ciências. Integrante do Grupo de Pesquisa Tuna - gênero, educação e diferença da Universidade Federal do Pampa e do Grupo de Pesquisa Sexualidade e Escola da Universidade Federal do Rio Grande. Endereço Eletrônico: fabianeunipampa@gmail.com 